\title{
ESTUDO EXPERIMENTAL DA TURBULÊNCIA INDUZIDA EM COLUNAS DE BOLHAS
}

\author{
D. WANKE $^{1 *}$, M. K. da SILVA ${ }^{1}$, R. K. DECKER ${ }^{1}$, H. F. MEIER ${ }^{1}$ \\ ${ }^{1}$ Universidade Regional de Blumenau, Departamento de Engenharia Química \\ *e-mail: diegownk@gmail.com
}

\begin{abstract}
RESUMO
Nos escoamentos multifásicos, gás-líquido, as estruturas turbulentas presentes na fase contínua e como elas interagem com a fase dispersa, são consideradas uma das mais importantes questões a serem avaliadas. Visto que estas estruturas e sua interação alteram as características do escoamento, como também a distribuição da fração volumétrica, podem ocasionar quedas de pressão e ainda influenciar nos mecanismos de transferência de massa, energia e quantidade de movimento. O presente trabalho tem como objetivo avaliar a influência da passagem das bolhas no movimento da fase líquida. Para tanto, estudos foram realizados em uma coluna de bolhas em escala laboratorial, a uma vazão volumétrica da fase dispersa de $5 \mathrm{~L} / \mathrm{min}$. A técnica experimental empregada foi a velocimetria por imagem de partícula (PIV). A estratégia utilizada para mensurar a velocidade da fase líquida, bem como sua flutuação e consequentemente a energia cinética turbulenta foi que após o escoamento estar estabilizado a injeção de ar na coluna de bolhas foi interrompida, após um curto intervalo de tempo onde todas as bolhas cessaram, a aquisição de dados foi realizada por aproximadamente $10 \mathrm{~s}$, para que fosse possível avaliar apenas a influência da passagem das bolhas na dinâmica do escoamento do líquido.
\end{abstract}

\section{INTRODUÇÃO}

Colunas de bolhas são equipamentos amplamente utilizados na indústria, devido à sua simples construção e operação; ainda por promover altas taxas de transferência de calor e massa. No entanto, sua fluidodinâmica é deveras complexa, a maneira como as fases interagem entre si e a turbulência gerada pela passagem das bolhas ainda é objeto de estudo.

As estruturas turbulentas da fase líquida e como elas interagem com a fase gasosa são consideradas uma das mais importantes questões em escoamentos gás - líquido, visto que as interações entre as fases e as estruturas turbulentas afetam as características do escoamento, distribuição da fração volumétrica, queda de pressão e os mecanismos de transferência de massa, energia e quantidade de movimento. A turbulência gerada pelas bolhas ao ascenderem na coluna é denominado de turbulência induzida. Já a turbulência gerada por uma grade é denominada de turbulência verdadeira (SATHE; JOSHI; EVANS, 2013; HOSOKAWA, TOMIYAMA, 2013).

Vários experimentos em escoamentos gás-líquido, mostram que a presença da fase dispersa, bolhas, altera consideravelmente a turbulência do líquido. As bolhas induzem flutuações que aumentam a turbulência global, alterando assim os mecanismos de produção, distribuição e dissipação desta (CHAHED; ROIG; MASBERNAT, 2003).

Segundo Rzehak e Krepper (2013b) o progresso na modelagem da turbulência em 
escoamentos borbulhantes é complicado pelo fato de mensurar, experimentalmente, a flutuação da velocidade do líquido é especialmente difícil com a presença das bolhas no escoamento. Portanto, apenas alguns experimentos foram realizados nestas condições que permitem uma comparação direta com os modelos para predição da intensidade da turbulência e da energia cinética turbulenta.

Ainda para Rzehak e Krepper (2013a), a presença de bolhas em escoamentos turbulentos de líquidos afeta a estrutura e a intensidade de movimentos turbulentos. Esta última alimenta a distribuição da fase dispersa e a taxa de coalescência e quebra das bolhas.

O desenvolvimento de um modelo adequado para a turbulência induzida pelas bolhas é um elemento fundamental a fim de obter um trabalho completo que permita predições adequadas em simulações em CFD para aplicações de engenharia que envolvam escoamentos multifásicos (RZEHAK; KREPPER, 2013a).

\subsection{Turbulência}

Muitos escoamentos presentes nas aplicações da engenharia são turbulentos, caracterizados por apresentarem flutuações de pressão e velocidade superpostas ao escoamento principal. As passagens de vórtices, de diversas escalas, são responsáveis por estas flutuações. A turbulência é responsável pelo aumento na resistência a um escoamento, porque tudo se passa como se a viscosidade apresentasse ser maior (MÖLLER; SILVESTRINI, 2004).

A turbulência é uma manifestação do comportamento caótico temporal e espacial, apresentado em escoamento de fluidos os quais possuem valores elevados do número de Reynolds. (MANSUR; VIEIRA; NETO, 2010).

De acordo com Mansur, Vieira e Neto (2010), os escoamentos turbulentos são altamente dissipativos, portanto implicam em grandes deformações. É necessária pelo menos uma fonte de energia, seja ela proveniente dos gradientes da velocidade média, do empuxo ou outras forças externas para a manutenção da turbulência. Normalmente o fornecimento desta energia se dá através das grandes escalas, ao passo que a dissipação ocorre nas pequenas escalas.

Os escoamentos turbulentos são tridimensionais e rotacionais, portanto eles apresentam muita vorticidade. Eles representam campos aleatórios de vorticidade, com predominância de estiramento vorticial, os quais são dissipados pela viscosidade (MANSUR; VIEIRA; NETO, 2010).

Dentro de um campo turbulento existem vórtices de diferentes tamanhos que contribuem para a energia cinética turbulenta total. Os de maior tamanho drenam energia do escoamento médio e a transferem para outros menores, e estes para outros menores ainda sucessivamente. Deste modo se cria um processo contínuo de transferência de energia, que vai em direção a uma escala de tamanhos onde tal energia passa a ser dissipada pelas tensões viscosas, atingindo um estado de equilíbrio. Esse processo é conhecido por cascata de energia e foi descrito por Kolmogorov (SOUZA et al., 2011), a Figura 1 apresenta um esquema desta cascata de energia.

Figura 1 - Esquema de Cascata de Energia

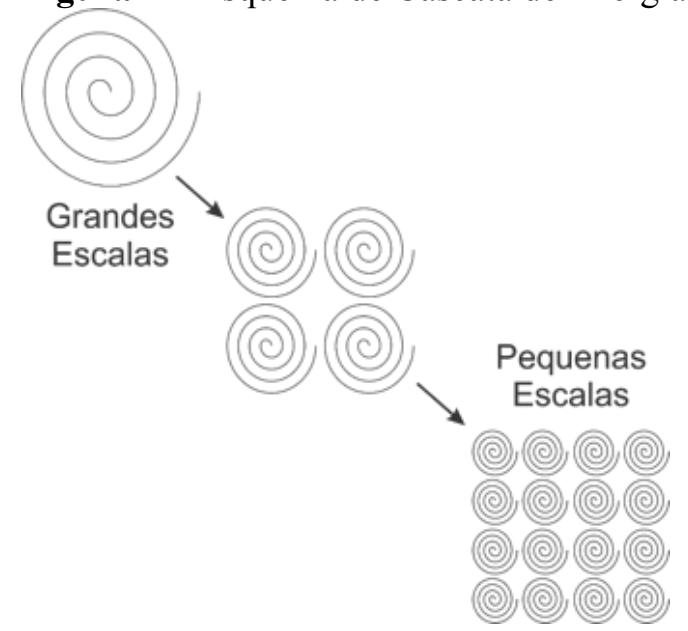

Fonte: Adaptado de FORDE (2012). 
Este trabalho tem como objetivo avaliar a influência da passagem das bolhas na turbulência da fase líquida em uma coluna de bolhas em escala laboratorial. Para tanto, medidas da velocidade axial da fase líquida, flutuações de velocidade e energia cinética turbulenta foram realizadas por meio da técnica de velocimetria por imagem de partícula (PIV). Os resultados mostraram que à medida em que as bolhas ascendem no líquido estagnado, vórtices são formados próximo ao centro da coluna, onde a passagem das bolhas ocorre. O mesmo acontece com as flutuações de velocidade, a qual possui um pico mais acentuado também próximo ao centro, onde consequentemente o valor da energia cinética turbulenta também é elevado.

\section{MATERIAIS E MÉTODOS}

\subsection{Descrição da Unidade Experimental}

A Unidade Experimental Coluna de Bolhas (UE-CB) se encontra instalada no laboratório de verificação e validação (LVV) do Departamento de Engenharia Química da Universidade Regional de Blumenau FURB.

A UE-CB é constituída por uma coluna de acrílico com $870 \mathrm{~mm}$ de altura, diâmetro interno de $144,2 \mathrm{~mm}$ e $3 \mathrm{~mm}$ de espessura.

A coluna opera em sistema bifásico, gás-líquido, onde é utilizado água destilada como fase líquida (fase contínua) e ar (fase dispersa) como fase gasosa.

O distribuidor de gás é composto por um prato dispersor de ar (malha porosa), cujo diâmetro das perfurações é de $130 \mu \mathrm{m}$, com porosidade total de $20 \%$, resultando em uma área total de borbulhamento igual a 24,75 $\mathrm{cm}^{2}$.

A vazão da fase gasosa é controlada por uma válvula tipo agulha, Fisher modelo 646, dotada de um sistema pneumático de abertura e fechamento. A vazão do ar é mensurada com um medidor de vazão para gases, modelo GMF 1142 da Dwyer Instruments, com capacidade de $0-100$ $\mathrm{L} / \min (6)$.

A unidade ainda possui um sistema de controle e sensores de pressão. Na Figura 2 é apresentado um esquema da unidade experimental.

Para utilização da Velocimentria por Imagem de Partícula necessita-se realizar algumas adaptações na estrutura da UE-CB. A fim de evitar os efeitos de refração e curvatura, adaptou-se uma caixa de acrílico,

Figura 2 - Esquema da Unidade Experimental Coluna de Bolhas (UE-CB)

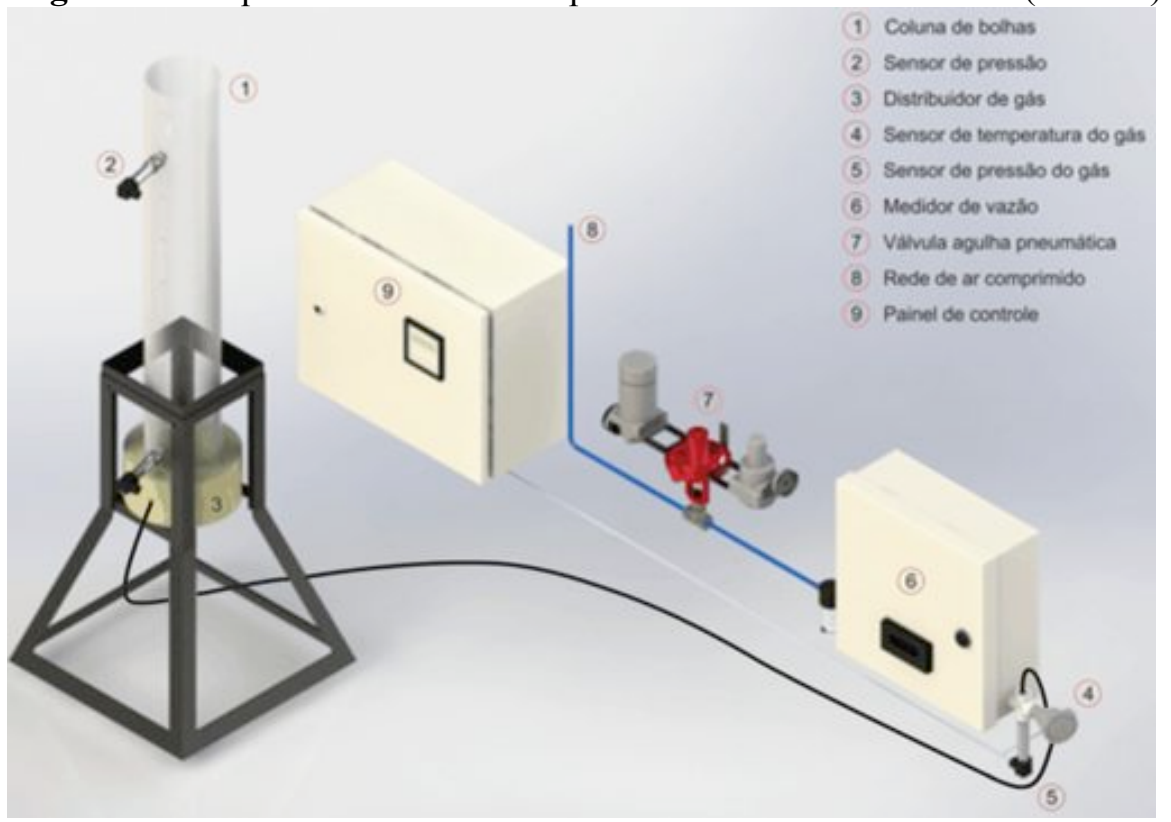


externamente a coluna, preenchida com o mesmo fluido como apresenta a Figura 3.

Figura 3 - Adaptação UE-CB

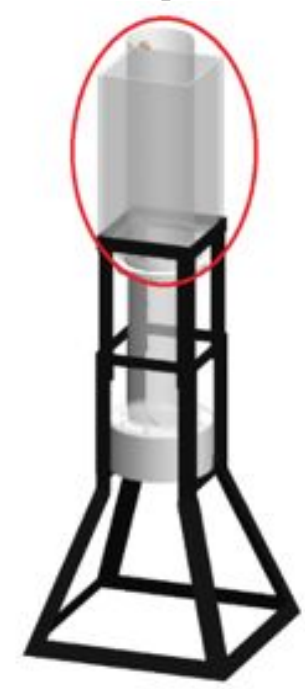

\subsection{Velocimetria por Imagem de Partículas} (PIV)

As medidas de velocidade da fase líquida, e suas flutuações foram realizadas por meio da técnica de velocimetria por imagem de partícula (PIV).

Em contraste com outras técnicas para mensurar a velocidade em fluidos, como as que utilizam Tubo de Pitot e a anemometria de fio e filme quente, a técnica PIV funciona de maneira não intrusiva. Deste modo, é possível utiliza-la em escoamentos de altas velocidades, na camada limite próxima à parede do escoamento, onde uma técnica intrusiva causaria perturbações ao escoamento (RAFFEL; WILLERT; KOMPENHANS, 1998). Ainda, por meio do PIV a medição de da velocidade instantânea é obtida em um campo espacial (janela de medição) e não em um único ponto.

$\mathrm{Na}$ maioria das aplicações do sistema PIV, necessita-se adicionar partículas traçadoras ao escoamento. Tais partículas são iluminadas pelo feixe de laser em dois instantes de tempo distintos, em intervalo de tempo pré-determinado, formando assim um par de imagens. As partículas também devem ter uma razão de carga adequada garantindo assim a sua identificação sem maiores dificuldades. Assim, cada par de imagens é analisado individualmente onde pela razão entre o deslocamento da partícula entre as duas imagens e o intervalo de tempo de ambas, tem-se o vetor velocidade associado à partícula traçadora avaliada (RAFFEL; WILLERT; KOMPENHANS, 1998). A Figura 4 apresenta um esquema simplificado do funcionamento do PIV.

Figura 4 - Esquema de Funcionamento do PIV

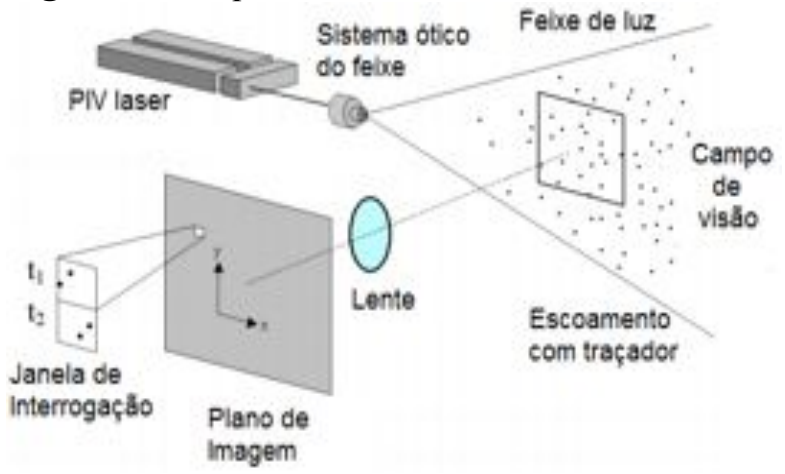

Fonte: Adaptado de LAVISION, 2007.

A técnica PIV é baseada na determinação de duas variáveis fundamentais da velocidade, deslocamento e tempo. Porém a técnica realiza essa medição de forma indireta, pois ela mensura a velocidade da partícula traçadora e não a velocidade do escoamento propriamente dito. Assim as propriedades das partículas devem ser verificadas, para que se comportem de acordo com o escoamento, evitando discrepâncias significantes entre seu movimento e o escoamento do fluido em estudo (RAFFEL; WILLERT; KOMPENHANS, 1998). As partículas traçadoras com número de Stokes menor que 0,1 se comportam como um fluido, e o movimento das mesmas representa com fidelidade o movimento do próprio fluido.

O sistema PIV utilizado para realizar as medições na unidade experimental é composto por uma câmera digital de alta performance com sistema CCD modelo PixelFly ${ }^{\mathrm{QE}}$. A câmera possui resolução de 
$1392 \times 1024$ pixel, com tamanho de $6,45 \times 6,45$ $\mu \mathrm{m}$. Um laser de dupla pulsação $\mathrm{Nd}: \mathrm{YAG}$ (Neodímio:Ítrio-Alumínio-Gálio), modelo ULTRA da Quantel, que emite comprimento de onda de $532 \mathrm{~nm}$, típico da luz verde. Utilizou-se o software DaVis 7.2 da LaVision para a aquisição de dados e processamento das imagens, obtendo assim, a velocidade da fase líquida, suas flutuações bem como a energia cinética turbulenta.

\subsection{Procedimento experimental}

Para a realização dos experimentos, tanto a coluna como a caixa acrílica, foram preenchidas com água destilada, a primeira até uma altura de $500 \mathrm{~mm}$ e a segunda em todo o seu volume. Isto tanto para a calibração do sistema quanto para a aquisição dos dados experimentais.

Para o desenvolvimento dos experimentos foi estabelecido inicialmente uma vazão de gás de $5 \mathrm{~L} / \mathrm{min}$ até sua estabilização. Na sequência a alimentação de gás na base da coluna foi interrompida, havendo um período de espera até que as últimas bolhas ascendessem, fato que ocorreu em aproximadamente $6 \mathrm{~s}$, e então foi iniciada a medição da dinâmica da velocidade da fase líquida. A janela de medição para a aquisição de dados inicia a $375 \mathrm{~mm}$ da base da coluna até o nível máximo de água situado a $500 \mathrm{~mm}$ em comprimento, e compreende todo o diâmetro da coluna para a largura $144 \mathrm{~m}$, ou seja uma janela de $125 \mathrm{~mm}$ de altura $\mathrm{x}$ $144 \mathrm{~mm}$ de largura.

Durante os experimentos foram retirados 50 pares de imagens em um intervalor de tempo de $6000 \mu \mathrm{s}$, com uma frequência de aquisição de $4,7 \mathrm{~Hz}$. Os parâmetros operacionais do sistema estão apresentados na Tabela 1 a seguir.
Tabela 1 - Parâmetros Operacionais do Sistema

\begin{tabular}{cc}
\hline Parâmetros & Valores \\
\hline$Q_{g}(\mathrm{~L} / \mathrm{min})$ & 5 \\
Potência Laser A (\%) & 43 \\
Potência Laser B (\%) & 46 \\
$\Delta t(\mu s)$ & 6000 \\
Pares de imagens & 50 \\
Frequência de & 4,7 \\
aquisição $(\mathrm{Hz})$ & \\
\hline
\end{tabular}

\section{RESULTADOS E DISCUSSÕES}

A dissipação da energia cinética turbulenta, foi estimada pelo método aproximado de análise dimensional apresentada pela Equação 1: (SHENG; MENG; FOX, 2005).

$\varepsilon=A \frac{u^{\prime 3}}{l}$

onde: A é uma constante de proporcionalidade de ordem $1, \varepsilon$ é a energia cinética turbulenta, $u^{3}$ é a flutuação da velocidade e $l$ é o comprimento integral de escala.

Para a estimativa qualitativa da dissipação da energia cinética turbulenta, o comprimento de escala integral utilizado foi o diâmetro da coluna.

As Figuras 5 e 6 apresentam mapas de vetores de velocidade axial média de líquido (a), energia cinética turbulenta (b) e a dissipação de energia cinética turbulenta (c). $\mathrm{Na}$ Figura 5 de $1 \mathrm{~s}$ até $5 \mathrm{~s}$, enquanto que na Figura 6 de $6 \mathrm{~s}$ a $10 \mathrm{~s}$. No campo vetorial, notam-se regiões onde existe a presença de estruturas vorticiais, tais vórtices são causados pela recirculação da fase líquida devido à passagem das bolhas. Ainda, observa-se que na região próxima à parede do lado esquerdo os vetores indicam a ascendência do líquido, enquanto que do lado direito, os vetores indicam o movimento decendente. 
Figura 5 - Evolução temporal dos vórtices, da energia cinética turbulenta e da dissipação da energia cinética turbulenta

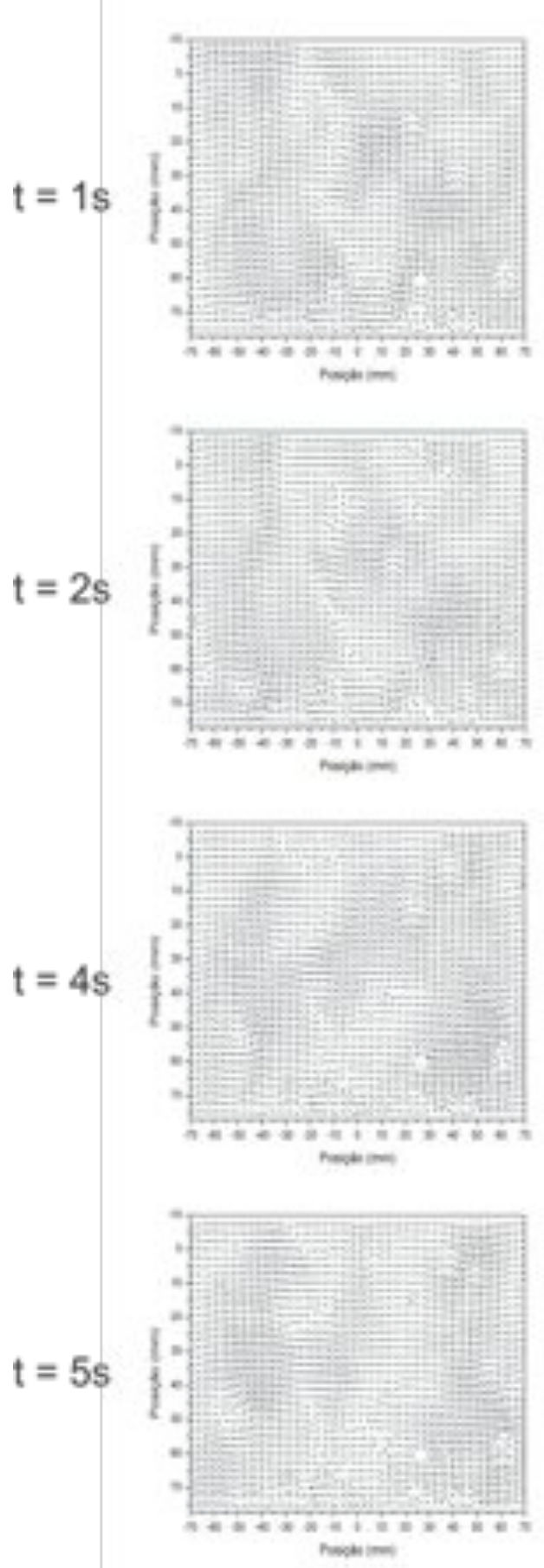

(a)
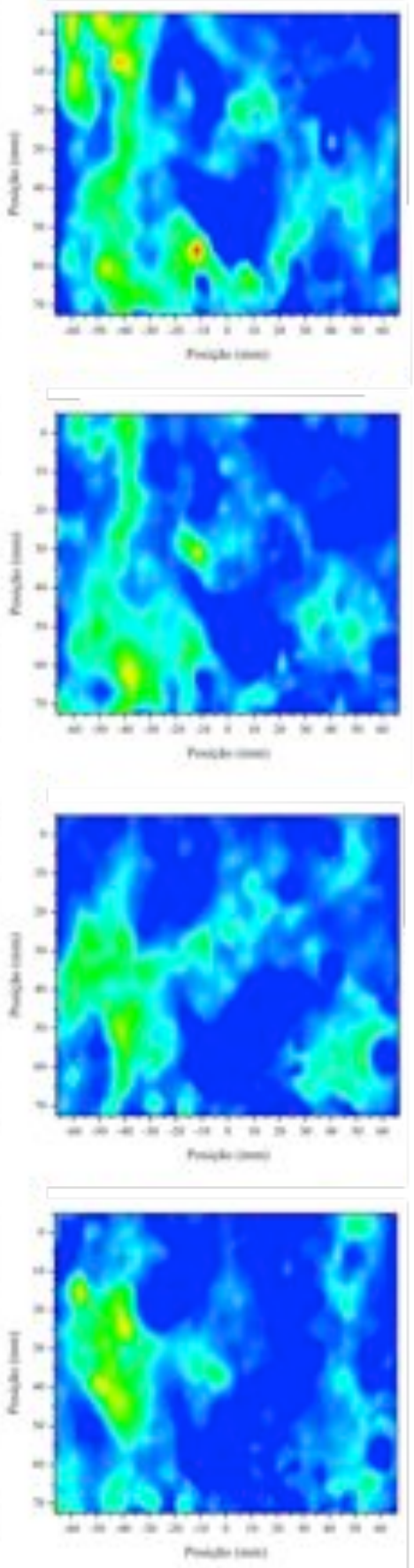

(b)
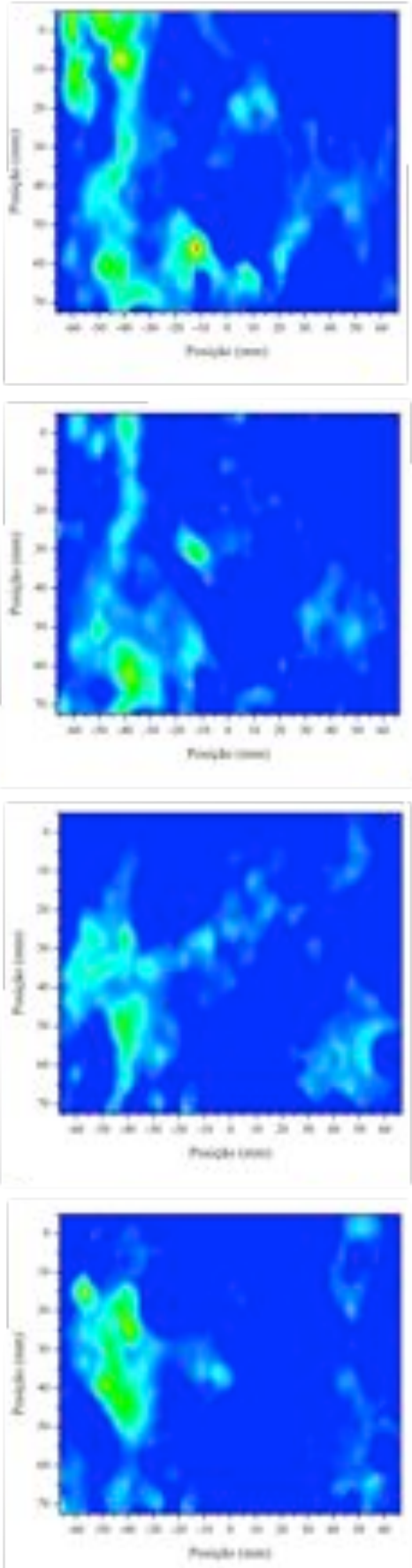

(c)

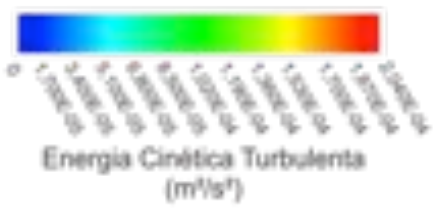

[mis'] 
Figura 6 - Evolução temporal dos vórtices, da energia cinética turbulenta e da dissipação da energia cinética turbulenta
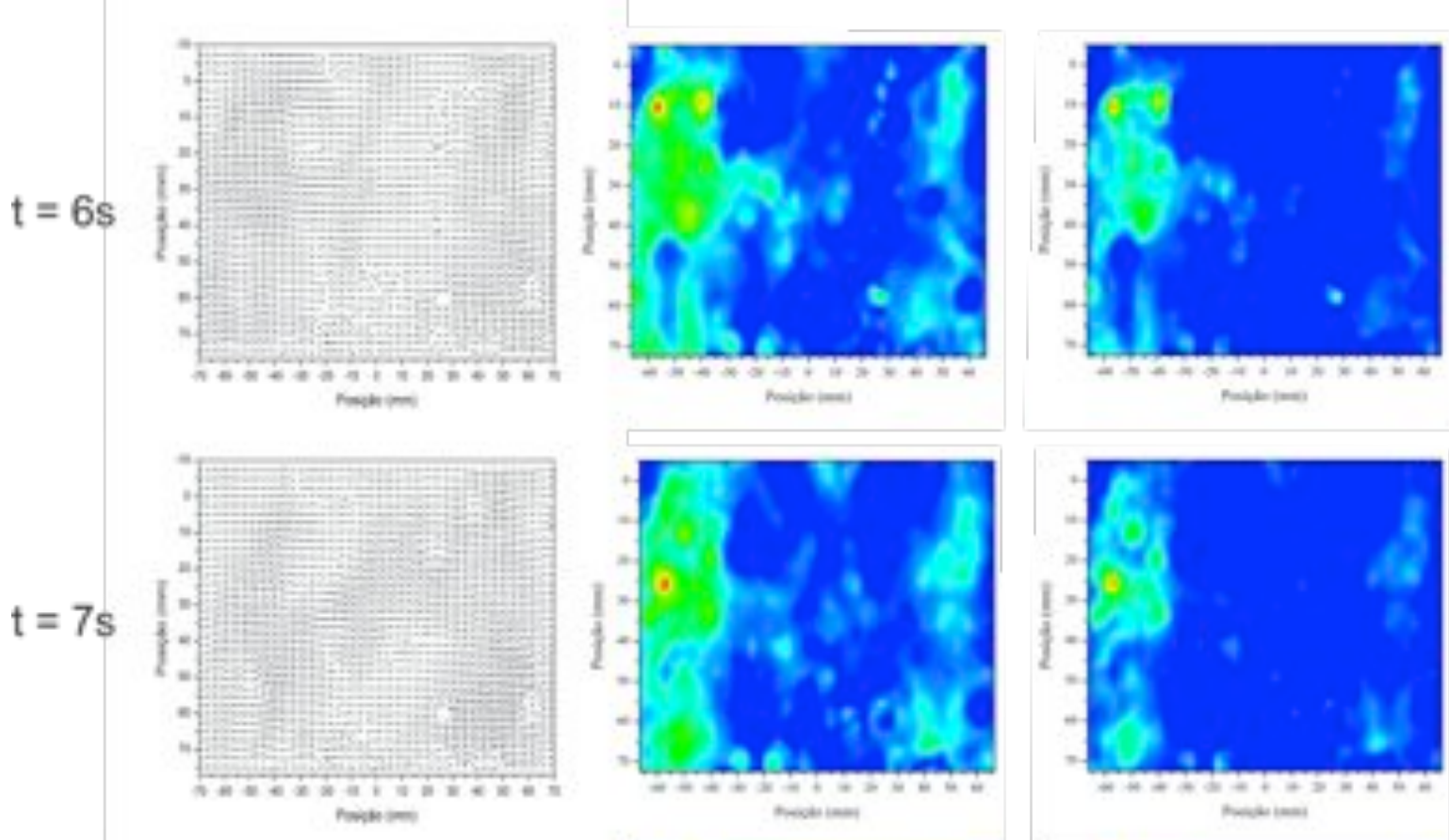

$\mathrm{t}=7 \mathrm{~s}$

homin

$\mathrm{t}=9 \mathrm{~s}$
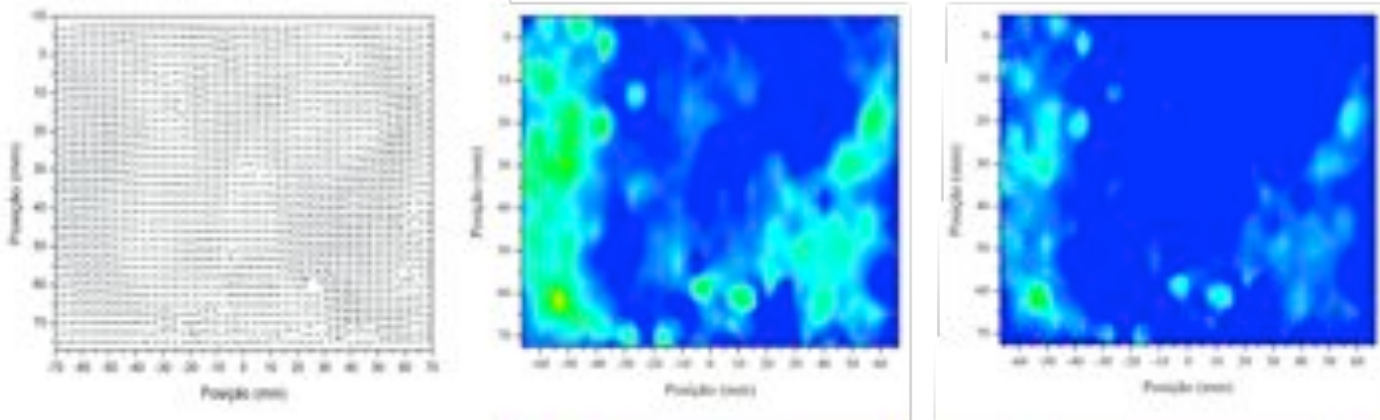

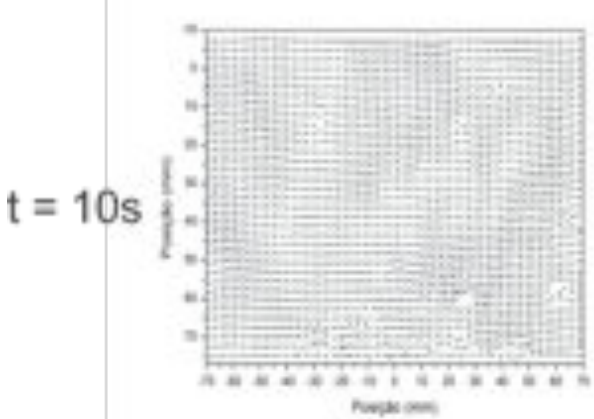

(a)

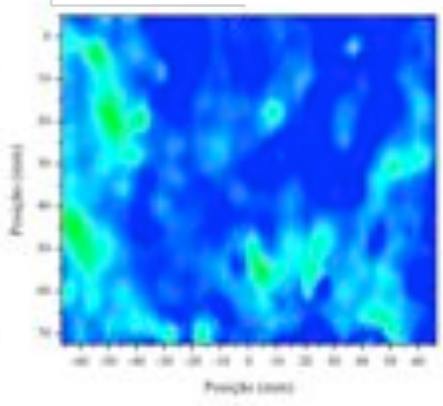

(b)

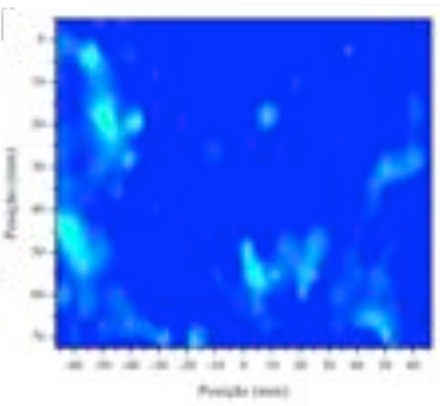

(c)

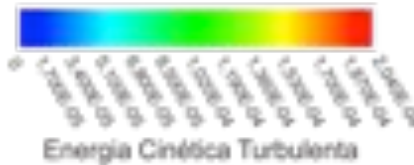
$(-m i s)$

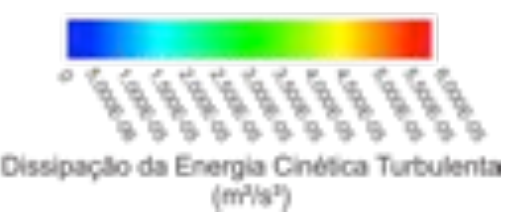


Com relação a energia cinética turbulenta, possui valores maiores nas regiões onde são produzidos os vórtices, próximo à parede do lado esquerdo da coluna, sua dissipação também é mais acentuada nesta região. Tal comportamento é observado desde do início do experimento até o tempo de 10s (Figura 6). No entanto, com o avanço, é dissipada devido atenuação de quantidade de movimento da fase líquida, visto não haver passagem contínua das bolhas no líquido.

\section{CONCLUSÕES}

A caracterização do escoamento turbulento gás/líquido em uma coluna de bolhas em escala experimental foi estudada por meio da técnica de medição não intrusiva PIV, a qual foi utilizada na obtenção de planos vetoriais de velocidade média da fase líquida, juntamente com a energia cinética turbulenta podendo assim calcular a dissipação da energia cinética turbulenta. Tais medições foram realizadas a fim de avaliar a turbulência que a passagem das bolhas introduz no padrão de escoamento do líquido.

As medidas foram efetuadas após a passagem das bolhas no líquido estagnado, os resultados mostraram um perfil oscilatório da pluma de bolhas característico deste tipo de escoamento. Tal oscilação forneceu perfis de velocidade axial de líquido com valor máximo próximo à parede do lado esquerdo da coluna, enquanto que no outro extremo ocorre a reversão do escoamento, ainda recirculações de líquido foram observadas próximo ao centro da coluna devido à passagem das bolhas.

Pode-se observar o comportamento de dissipação da energia cinética turbulenta através dos planos de dissipação da mesma, como também avaliando a própria energia cinética turbulenta ao longo do intervalo de tempo que ocorreram as medições.

Esta análise qualitativa da energia cinética turbulenta e a sua dissipação mostrou-se coerente quando comparado aos planos vetoriais da velocidade média do líquido, onde é possível identificar os vórtices nas regiões centrais e com maiores velocidades na região próxima a parede esquerda da coluna de bolhas.

Através dos dados de velocidade e energia cinética turbulenta pode-se calcular e obter uma estimativa da dissipação da energia cinética turbulenta. Esta estimativa também se mostrou adequada, pois observou-se que nas regiões onde possuíam maior energia cinética turbulenta apresentavam consequentemente maior dissipação e ambas foram decaindo com o passar do tempo.

\section{NOMENCLATURA}

$\mathrm{k}$ - energia cinética turbulenta $\left(\mathrm{m}^{2} / \mathrm{s}^{2}\right)$

$\varepsilon$ - dissipação da energia cinética turbulenta $\left(\mathrm{m}^{2} / \mathrm{s}^{3}\right)$

1 - comprimento de escala integral $(\mathrm{m})$

PIV - velocimetria por imagem de partícula.

$\mathrm{Q}_{\mathrm{g}}$ - vazão de gás ( $\left.\mathrm{L} / \mathrm{min}\right)$ de bolhas.

UE-CB - unidade experimental coluna

\section{REFERÊNCIAS}

CHAHED, J.; ROIG, V.; MASBERNAT, L. Eulerian-Eulerian Two-Fluid Model for Turbulent Gas-Liquid Bubbly Flows. International Journal of Multiphase Flow, n. 29, p.23-49, 2003.

FORDE, Olav Oyvind. Analysis of the Turbulent Energy Dissipation. 2012. 44 f. Dissertação (Mestrado) - Curso de Design de Produto e Manufatura, Energia e Engenharia de Processos, Norwegian University of Science and Technology, Noruega, 2012.

SHENG, J.; MENG, H.; FOX, R. O. A Large Eddy PIV Method for Turbulence Dissipation 
Rate Estimation, Chemical Engineering Science, n. 55, p.4423-4434, 2005.

HOSOKAWA, S.; TOMIYAMA, A. Bubbleinduced Pseudo Turbulence in Laminar Pipe Flows. International Journal of Heat and Fluid Flow, n. 40, p.97-105, fev. 2013.

LAVISION. Product-Manual: FlowMaster. Göttinngen: 2007.

MANSUR, S. S.; VIEIRA, E. del R.; SILVEIRA NETO, A. Turbulência. Rio de Janeiro: Abcm, v.7, 2010. 379 p.

MÖLLER, S. V.; SILVESTRINI, J. H. Turbulência. Porto Alegre: ABCM, v.4, 2004. 231 p.

RZEHAK, R.; KREPPER, E. CFD Modeling of Bubble-Induced Turbulence. International Journal Of Multiphase Flow, n. 55, p.138155, 2013a.

RAFFEL, M.; WILLERT, C. E.; KOMPENHANS, J. Particle image velocimetry: a practical guide. Berlin; New York: Springer, 1998. xvi, 253 p. (Experimental fluid mechanics).

RZEHAK, R.; KREPPER, E. Bubble-induced Turbulence: Comparison of CFD Models. Nuclear Engineering And Design, n. 258, p.57-65, $2013 b$.

SATHE, M.; JOSHI, J.; EVANS, G. Characterization of Turbulence in Rectangular Bubble Column. Chemical Engineering Science, v. 100, p.52-68, ago. 2013.

SOUZA, J. F. A.; OLIVEIRA, L. R.; AZEVEDO, L. L.; SOARES, I. D.; MATA, M. M. Uma revisão sobre a turbulência e sua modelagem. Revista Brasileira de Geofísica, v. 29, n. 1, p.21-41, 2011.
URSEANU, M.I. Scaling up bubble column reactors. 2000. f. Dissertação (Mestrado) Faculty of Science, Amsterdam, 2000. Disponível em: $<$ http://dare.uva.nl/document/83975>. Acesso em: 27 fev. 2013.

\section{AGRADECIMENTOS}

Os autores agradecem o apoio financeiro da PETROBRAS, termo de cooperação 0050.0070334.11.9, que garantiu o desenvolvimento deste trabalho. 